\title{
The effect of aerobic training on CXL5, tumor necrosis factor $\alpha$ and insulin resistance index (HOMA-IR) in sedentary obese women
}

\author{
FARZAD ZEHSAZ, NEGIN FARHANGI, LAMIA MIRHEIDARI
}

Department of Physical Education \& Sport Sciences, College of Humanities and Educational Sciences, Tabriz Branch, Islamic Azad University, Tabriz, Iran

\begin{abstract}
The purpose of the present study was to investigate the effects of a 12-week training program on serum CXC ligand 5, tumor necrosis factor $\alpha(T N F-\alpha)$ and insulin resistance index in obese sedentary women. To this end, twenty-four obese sedentary women were evaluated before and after a 12-week exercise program including a brief warm-up, followed by $\sim 5$ min per session of aerobic exercise at an intensity of $60-75 \%$ of age-predicted maximum heart rate ( 300 kcal/day), followed by a brief cool down, five times per week. After the exercise program, body weight, waist circumference, waist to hip ratio, percentage body fat mass, fasting glucose and insulin of participants were decreased. Furthermore, serum CXCL5 levels were significantly decreased from $2693.2 \pm 375.8$ to $2290.2 \pm 345.9 \mathrm{pg} / \mathrm{ml}$ $(p<0.001)$ after the training program, which was accompanied with significantly decreased HOMA-IR $(p<0.001)$ and $T N F-\alpha(p<0.001)$. Exercise training induced weight loss resulted in a significant reduction in serum CXCL5 concentrations and caused an improvement in insulin resistance in obese sedentary women.
\end{abstract}

Key words: CXCL5, fasting glucose, training, HOMA-IR, TNF- $\alpha$.

(Centr Eur J Immunol 2014; 39 (3): 365-369)

\section{Introduction}

In developing countries, the prevalence of obesity as the epidemic of the $21^{\text {st }}$ century continues to rise at younger ages [1]. Insulin resistance is the crucial pathophysiological feature of obesity and type 2 diabetes, high calorie intake and lack of exercise are involved in its etiology. Exercise training is recognized as an effective prescription for both prevention and reversal of insulin resistance; however, it is still unknown how exercise training ameliorates insulin resistance [2].

White adipose tissue (WAT) is primarily involved in energy storage in the form of triglycerides, and energy release in the form of free fatty acids. However, WAT is no longer considered only as a fat storage organ [3,4]. Adipose is not only the important target tissue of insulin but also an endocrine organ that can secret multiple cytokines $[5,6]$. Increased WAT mass, such as observed in obese subjects is correlated with chronic systemic inflammatory response, demonstrated by increased infiltration of macrophages in WAT [7, 8]. This inflammatory state results in the development of obesity-associated pathologies including atherosclerosis, hypertension, non-alcoholic steatohepatitis, and insulin resistance. These obesity-associated pathologies are a result, at least in part, of changes in the secretion of adipose tissue derived factors, and illustrates the link between inflammatory state and metabolic response [9].

Chemokines are proinflammatory cytokines that stimulate leukocyte chemoattraction and are produced in response to infectious and other inflammatory stimuli by a number of different cell types [10]. CXC ligand 5 (CXCL5), an adipokine with high levels of expression and secretion in the macrophage fraction of WAT belonging to the chemokine family [11], has also been suggested as a link between obesity and insulin resistance [12]. CXCL5 protein is detectable in human serum, and its circulating levels were found dramatically increased in serum of human obese compared with lean subjects. Conversely, CXCL5 concentration is decreased in obese subjects after a weight reduction program (by metformin), or in obese non-insulin-resistant, compared with insulin-resistant subjects [13].

On the other hand, several lines of evidence suggest that tumor necrosis factor $\alpha$ (TNF- $\alpha)$ is involved in the obesity-related insulin resistance. For instance, it has been observed in animals and humans that obesity is associated with an overexpression of TNF- $\alpha$ as well as other proinflammatory cytokines in adipose tissue (AT) [13]. Further

Correspondence: Farzad Zehsaz, Department of Physical Education \& Sport Sciences, College of Humanities and Educational Sciences, Tabriz Branch, Islamic Azad University, Tabriz, Iran, e-mail: f-zehsaz@iaut.ac.ir 
analysis suggests that TNF- $\alpha$ which is a well-characterized cytokine with insulin resistance [14], could trigger the expression of CXCL5 in WAT through the nuclear factor $\beta$ pathway [12].

A sedentary lifestyle contributes to the increased risk of developing type 2 diabetes [15]. It is generally accepted that prolonged physical exercise increases insulin sensitivity and might be useful in the prevention of type 2 diabetes [15-17] and exercise training has proved to be useful in the management of insulin-resistant states including obesity [18]. External factors such as nutritional status, stress, physical exercise, infection or trauma, will affect WAT biology through various signaling pathways $[7,8]$. However, there is no information about the impact of physical exercise on CXCL5 and whether this impact is related to insulin resistance and obesity. Therefore, we examined the effect of exercise training on serum CXCL5 and TNF- $\alpha$ levels in obese women with insulin resistance in the present study.

\section{Material and methods}

\section{Subjects}

One hundred sedentary $(<20$ min exercise twice per week) obese women having normal menstrual cycles vol-

Table 1. Anthropometric and biochemical characteristics of subjects at baseline. Data are expressed as means \pm SD

\begin{tabular}{lccc}
\hline $\begin{array}{l}\text { Group/ } \\
\text { characteristics }\end{array}$ & Control & Experimental & $p$ value \\
\hline Age (years) & $35.25 \pm 6.05$ & $35.17 \pm 5.37$ & 0.97 \\
\hline Height $(\mathrm{m})$ & $1.61 \pm 0.05$ & $1.62 \pm 0.04$ & 0.80 \\
\hline Weight $(\mathrm{kg})$ & $80.25 \pm 5.36$ & $80.29 \pm 6.28$ & 0.98 \\
\hline $\begin{array}{l}\text { Body mass index } \\
\text { (BMI) }\left(\mathrm{kg} / \mathrm{m}^{2}\right)\end{array}$ & $30.76 \pm 1.28$ & $30.56 \pm 1.59$ & 0.73 \\
\hline $\begin{array}{l}\text { Waist circumference } \\
\text { (WC) }(\mathrm{cm})\end{array}$ & $94.25 \pm 6.74$ & $95.46 \pm 7.05$ & 0.67 \\
\hline Waist to hip ratio & $0.89 \pm 0.02$ & $0.88 \pm 0.02$ & 0.46 \\
\hline Fat $(\%)$ & $32.96 \pm 1.75$ & $34.04 \pm 1.99$ & 0.17 \\
\hline $\begin{array}{l}\text { Serum fasting glucose } \\
\text { (mmol/l) }\end{array}$ & $5.86 \pm 0.22$ & $5.80 \pm 0.31$ & 0.59 \\
\hline $\begin{array}{l}\text { Serum fasting insulin } \\
(\mu \mathrm{U} / \mathrm{ml})\end{array}$ & $13.37 \pm 2.19$ & $13.61 \pm 2.74$ & 0.82 \\
\hline HOMA-IR & $3.48 \pm 0.56$ & $3.50 \pm 0.68$ & 0.93 \\
\hline TNF- $\alpha$ (pg/ml) & $6.14 \pm 1.42$ & $6.34 \pm 2.00$ & 0.78 \\
\hline sTNF-R1 (ng/ml) & $2.88 \pm 0.84$ & $2.79 \pm 0.71$ & 0.77 \\
\hline sTNF-R2 (ng/ml) & $5.49 \pm 0.51$ & $5.54 \pm 0.60$ & 0.81 \\
\hline CXCL5 (pg/ml) & $2776.5 \pm 304.7$ & $2693.2 \pm 375.8$ & 0.55 \\
\hline
\end{tabular}

unteered to participate in this study. Insulin resistance was calculated as [fasting glucose $(\mathrm{mmol} / \mathrm{l}) \times$ fasting insulin $(\mu \mathrm{U} / \mathrm{ml}) / 22.5]$ by the homeostasis model assessment (HOMA) [19]. Then twenty four subjects (HOMA-IR $\geq 2.5$ ) [20] were recruited for this study. The subjects were randomly assigned to two groups [the first: control (non-training) and the second: experimental (training)]. The characteristics of the subjects are summarized in Table 1 .

Obesity was defined with BMI according to the Asia-Pacific criteria (APC-BMI $\geq 25 \mathrm{~kg} / \mathrm{m}^{2}$ ) [21]. To define central obesity, we used the APC for central obesity based on waist circumference (APC-WC) as defined by the World Health Organization (WHO) $(\mathrm{WC} \geq 80 \mathrm{~cm})$ [21]. Percentage body fat mass was determined by bioelectrical impedance analysis (Omron HBF-300, Tokyo, Japan). They had a stable body weight $(<2 \mathrm{~kg} / 6$ months weight change) and a sedentary lifestyle $(<20$ min exercise twice per week). All the subjects were premenopausal and were not on hormone replacement therapy. Subjects were screened by the medical history questionnaire, physical examination, fasting blood profile, and a graded exercise treadmill test in an attempt to exclude those with cardiovascular disease. We also excluded candidates who smoked, had diabetes or any other major illness, or were taking medications that could have affected laboratory test results. Informed consent was obtained from all participants before the start of the study, and the research ethics committee of our institution approved the study $(\mathrm{NF} / 25.12 .1392)$ and the procedures followed were in accordance with the ethical standards of the responsible committee on human experimentation (institutional and national) and with the Helsinki Declaration of 1975.

\section{Exercise protocol}

All the training sessions were supervised by a physician, and heart rate and blood pressure were monitored during exercise. Participants were encouraged to train five times per week, consisting of a brief warm-up, followed by $\sim 45 \mathrm{~min}$ per session of aerobic exercise at an intensity of $60-75 \%$ of age-predicted maximum heart rate $(\sim 300 \mathrm{kcal} /$ day), followed by a brief cool down. The training program started at $40 \%$ of the observed maximal heart rate and gradually increased to $60-75 \%$ of the maximal heart rate by week 12 [22]. Aerobic exercise training included treadmill walking/running (M901T, Motus Co., Seoul, Korea) and cycling (CY8866R, Sunny Co., Seoul, Korea).

\section{Laboratory measurements}

All the measurements were obtained at baseline and after completing a 12-week exercise training protocol. Blood samples were drawn after a 12-h overnight fast and were kept at $-80^{\circ} \mathrm{C}$ for subsequent assay. Analyses were taken at least $48 \mathrm{~h}$ after the last bout of exercise. In the 
control group, measurements were taken at baseline and after 12 weeks. Serum insulin was measured by a commercial chemiluminescence assay kit (Cobas®, USA) (intra-Assay CV: $1.9 \%$, inter-Assay CV: $2.6 \%$ ) and serum glucose was measured by a glucose oxidase method kit (Pars Azmoon, IRAN). Serum TNF- $\alpha$ concentrations were determined using high-sensitivity ELISA (Biosource International, Camarillo, CA, USA). The lower limit of detection for TNF- $\alpha$ was $0.5 \mathrm{pg} / \mathrm{ml}$, and the intra- and inter-assay coefficients of variation were $<7 \%$. Soluble TNF-R1 and TNF-R2 in serum were determined using commercially available ELISA kits (Biosource Europe, Fleunes, Belgium). The minimum detectable concentrations for TNF-R1 and TNF-R2 were estimated to be $50 \mathrm{pg} / \mathrm{ml}$ and $0.1 \mathrm{ng} / \mathrm{ml}$, respectively. The serum CXCL5 was determined in duplicate by ELISA with Duoset kit (DY254; R\&D Systems, Minneapolis, MN) as recommended by the manufacturer. The ELISA system had an intra-assay coefficient of variation of 3-8\% and an inter-assay coefficient of variation of $4-10 \%$, respectively.

\section{Statistical analysis}

All statistical analyses were performed with SPSS program (version 19, SPSS, Inc., Chicago, IL). Values were expressed as mean \pm standard deviation (SD). The Kolmogorov-Smirnov test was used to determine the normality of distribution, and variables were found to be normally distributed. Independent sample $t$-test was used to evaluate homogeneous groups at baseline. Paired $t$-test was used for comparison of variables before and after exercise. Repeated Measures ANOVA was used to evaluate differences between control and experimental groups. $P$-values less than 0.05 were considered statistically significant.

\section{Results}

Clinical and biochemical characteristics of the study subjects before exercise training are presented in Table 1 . The first results showed that there were no age, weight, height, BMI and other factors differences among the groups. After 12 weeks of the exercise training program, all subjects had lost weight, which was accompanied with a significantly decreased BMI, waist circumference, waist to hip ratio, percent body fat mass, glucose, and HOMA-IR. Glucose concentrations before and after the training program were $5.80 \pm 0.31$ and $5.27 \pm 0.17 \mathrm{mmol} / \mathrm{l}$, respectively $(p<0.001)$. Insulin concentration declined significantly $(p<0.001)$ from $13.61 \pm 2.74$ to $10.62 \pm 2.28$ $\mu \mathrm{U} / \mathrm{ml}$, in response to 12 -week exercise training, while the changes in the control group after 12 weeks were not statistically significant. Insulin resistance index, assessed by HOMA-IR was reduced significantly $(p<0.001)$ following 12-week training, with no significant changes in the control group. Furthermore, serum CXCL5 levels were also significantly decreased from $2693.2 \pm 375.8$ to 2290.2 $\pm 345.9 \mathrm{pg} / \mathrm{ml}(p<0.001)$ after the training program. Serum TNF- $\alpha$, sTNF-R1 and STNF-R2 concentrations were significantly decreased after 12 -week physical training in the experimental group compared to the control group ( $p=0.05 ; p=0.05 ; p=0.01$, respectively) (Table 2 ).

\section{Discussion}

The present study demonstrated that exercise training with weight loss can reduce CXCL5 levels in obese women. The significant reduction observed in CXCL5 levels and the different indicators of metabolic syndrome after the training program confirmed our hypotheses that ex-

Table 2. Comparison of differences between and within groups after a 12-week training program. Data are expressed as means $\pm \mathrm{SD}$

\begin{tabular}{lccccc}
\hline \multirow{2}{*}{ Group/characteristics } & \multicolumn{2}{c}{ Post Test } & \multicolumn{2}{c}{$\boldsymbol{p}$-value within groups } & \multirow{p}{c}{$\begin{array}{c}\text {-value between } \\
\text { groups }\end{array}$} \\
\cline { 2 - 5 } & Control & Experimental & Control & Experimental & \\
\hline Weight $(\mathrm{kg})$ & $80.54 \pm 5.06$ & $75.25 \pm 5.67$ & 0.15 & $<0.001$ & 0.05 \\
\hline Body mass index $(\mathrm{BMI})\left(\mathrm{kg} / \mathrm{m}^{2}\right)$ & $30.88 \pm 1.26$ & $28.64 \pm 1.37$ & 0.13 & $<0.001$ & 0.04 \\
\hline Waist circumference $(\mathrm{WC})(\mathrm{cm})$ & $93.08 \pm 7.07$ & $88.62 \pm 6.48$ & 0.34 & $<0.001$ & 0.05 \\
\hline Waist to hip ratio & $0.88 \pm 0.02$ & $0.84 \pm 0.02$ & 0.17 & $<0.001$ & 0.01 \\
\hline Fat $(\%)$ & $33.58 \pm 2.60$ & $29.46 \pm 1.48$ & 0.33 & $<0.001$ & 0.05 \\
\hline Serum fasting glucose $(\mathrm{mmol} / \mathrm{l})$ & $5.83 \pm 0.21$ & $5.27 \pm 0.17$ & 0.56 & $<0.001$ & 0.002 \\
\hline Serum fasting insulin $(\mu \mathrm{U} / \mathrm{ml})$ & $13.42 \pm 2.07$ & $10.62 \pm 2.28$ & 0.45 & $<0.001$ & 0.05 \\
\hline HOMA-IR & $3.48 \pm 0.55$ & $2.49 \pm 0.53$ & 0.96 & $<0.001$ & 0.05 \\
\hline TNF- $\alpha(\mathrm{pg} / \mathrm{ml})$ & $6.13 \pm 1.39$ & $3.10 \pm 1.91$ & 0.41 & $<0.001$ & 0.05 \\
\hline sTNF-R1 $(\mathrm{ng} / \mathrm{ml})$ & $2.87 \pm 0.81$ & $1.69 \pm 0.71$ & 0.37 & $<0.001$ & 0.05 \\
\hline sTNF-R2 $(\mathrm{ng} / \mathrm{ml})$ & $5.51 \pm 0.50$ & $4.27 \pm 0.58$ & 0.31 & $<0.001$ & 0.01 \\
\hline CXCL5 $(\mathrm{pg} / \mathrm{ml})$ & $2765.3 \pm 315.3$ & $2290.2 \pm 345.9$ & 0.06 & $<0.001$ & 0.05 \\
\hline
\end{tabular}


ercise training can provide an effective approach to combating the harmful factors associated with obesity. As many other previous studies have clarified [23, 24], this study has verified that exercise is effective in improving blood glucose and insulin resistance. Some of the insulin desensitizing effects observed during obesity development are mediated by adipokine. Chavey et al. proposed that circulating levels of CXCL5 are associated with human obesity and insulin resistance, and demonstrated inhibitory effects of the cytokine in insulin-induced glucose transport in muscle cells [12]. Consistent with a role in insulin resistance, it has been shown that treatment of obese, insulin resistant mice with either neutralizing anti-CXCL5 antibodies or CXCR2 antagonists results in an overall decrease in fasting glycemia, and improved insulin sensitivity. The positive association of CXCL5 concentration with obesity suggested that this chemokine could be a mediator of insulin resistance. The biological effects of CXCL5 are mediated through interaction with the chemokine receptor CXCR2. A more detailed analysis suggested that CXCL5 was inhibiting, insulin signaling through activation of the JAK/STAT pathway, and consequently through increasing the expression of SOCS2, which is a known inhibitor of the insulin receptor, and increasing the activity of Stat5 signaling up to 2.5 -fold. CXCL5 could block insulin signaling in muscle through activation of the Jak/STAT/ SOCS pathway through the CXCR2 receptor. Moreover, treatment with anti-CXCL5 improved glucose tolerance during an intraperitoneal glucose tolerance test in both mouse models of obesity [12].

Further analysis suggests that TNF- $\alpha$, which is a well-characterized cytokine with insulin resistance [14], could trigger the expression of CXCL5 in WAT through the nuclear factor- $\beta$ (NFא $\beta$ ) pathway. Moreover, deletion of TNF- $\alpha$ receptor in WAT from obese mice abolished CXCL5 mRNA expression in this tissue, proving that TNF- $\alpha$ is a master regulator of CXCL5 during obesity. In addition this suggests that CXCL5 mediates the effects of TNF- $\alpha$ on insulin resistance. Thiazolidinediones, which are PPAR $\gamma$ agonists used clinically as insulin sensitizers, reduce CXCL5 expression, likely through a direct reduction in $\mathrm{NF} \kappa \beta$ transcriptional regulation of CXCL5 promoter in response to TNF- $\alpha$ stimulation [12]. TNF- $\alpha$ was rapidly cleared from the circulation and levels were significantly lowered. Therefore, the assessment of the TNF- $\alpha$ system activity on the basis of serum TNF receptor concentrations seems to be more reliable, because these proteins are easily detectable in serum and remain elevated for longer periods of time [25]. However, we observed significant decreases in TNF- $\alpha$, soluble TNF-R1 and TNF-R2 levels after exercise. Previous studies reported a marked decrease in TNF- $\alpha$ expression in adipose tissue [26, 27] and a decrease in circulating TNF- $\alpha[28,29]$ after weight loss. We also observed a slight decrease in body weight, waist circumference and fat mass, which is attributed mainly to the increase in physical activity. Our results are in line with previous research that found considerable reductions in serum TNF- $\alpha$ and soluble TNF receptors after exercise. These results suggest that exercise may weaken an activated TNF- $\alpha$ system in obesity [30].

\section{Conclusions}

In conclusion, we found that serum CXCL5 levels were reduced after a 12-week exercise training program in sedentary obese women. We demonstrated that a reduction in serum concentrations of CXCL5 after exercise in humans can be associated with the TNF system and insulin resistance as measured by the HOMA-IR. Inhibiting CXCL5 secretion or function in obese individuals not only ameliorates their insulin sensitivity, but could also decrease the risk of developing other major obesity-related pathologies [12]. Reduction in CXCL5 concentration by exercise training program may be therefore considered as a therapeutic tool for the treatment of the metabolic syndrome.

The authors declare no conflicts of interest.

\section{References}

1. World Health Organization. Fact sheet: obesity and overweight. Internet: http://www.who.int/dietphysicalactivity/ publications/facts/obesity/en/ (accessed 5 December 2013).

2. Sun H, Deng X, Xiao F, et al. (2009): Role of exercise training on insulin resistance and TNF- $\alpha$ in high-fat diet rats. Front Med China 3: 403-407.

3. Trujillo ME, Scherer PE (2006): Adipose tissue-derived factors: impact on health and disease. Endoc Rev 27: 762-778.

4. Ottaviani E, Malagoli D, Franceschi C (2011): The evolution of the adipose tissue: a neglected enigma. Gen Comp Endocrinol 174: 1-4.

5. Galic S, Oakhill JS, Steinberg GR (2010): Adipose tissue as an endocrine organ. Mol Cell Endocrinol 316: 129-139.

6. Coelho M, Oliveira T, Fernandes R (2013): Biochemistry of adipose tissue: an endocrine organ. Arch Med Sci 9: 191-200.

7. Xu H, Barnes GT, Yang Q, et al. (2003): Chronic inflammation in fat plays a crucial role in the development of obesity-related insulin resistance. J Clin Invest 112: 1821-1830.

8. Weisberg SP, McCann D, Desai M, et al. (2003): Obesity is associated with macrophage accumulation in adipose tissue. J Clin Invest 112: 1796-1808.

9. Hotamisligil GS (2006): Inflammation and metabolic disorders. Nature 444: 860-867.

10. Walz A, Schmutz P, Mueller C, et al. (1997): Regulation and function of the CXC chemokine ENA-78 in monocytes and its role in disease. J Leukoc Biol 62: 604-611.

11. Walz A, Burgener R, Car B, et al. (1991): Structure and neutrophil-activating properties of a novel inflammatory peptide (ENA-78) with homology to interleukin 8. J Exp Med 174: 1355-1362.

12. Chavey C, Lazennec G, Lagarrigue S, et al. (2009): CXC ligand 5 is an adipose-tissue derived factor that links obesity to insulin resistance. Cell Metab 9: 339-349. 
13. Kern PA, Ranganathan S, Li C, et al. (2001): Adipose tissue tumor necrosis factor and interleukin-6 expression in human obesity and insulin resistance. Am J Physiol Endocrinol Metab 280: 745-751.

14. Hivert MF, Sullivan LM, Fox CS, et al. (2008): Associations of adiponectin, resistin, and tumor necrosis factor with insulin resistance. J Clin Endocrinol Metab 93: 3165-3172.

15. Eriksson J, Taimela S, Koivisto VA (1997): Exercise and the metabolic syndrome. Diabetologia 40: 125-135.

16. Helmrich SP, Ragland DR, Leung RW, et al. (1991): Physical activity and reduced occurrence of non-insulin-dependent diabetes mellitus. N Engl J Med 325: 147-152.

17. Mayer-Davis EJ, D'Agostino R, Karter AJ, et al. (1998): Intensity and amount of physical activity in relation to insulin sensitivity. JAMA 279: 669-674.

18. Perez-Martin A, Raynaud E, Mercier J (2001): Insulin resistance and associated metabolic abnormalities in muscle: effects of exercise. Obes Rev 2: 47-59.

19. Matthews DR, Hosker JP, Rudenski AS, et al. (1985): Homeostasis model assessment: insulin resistance and beta-cell function from fasting plasma glucose and insulin concentrations in man. Diabetologia 28: 412-419.

20. Keskin M, Kurtoglu S, Kendirci M, et al. (2005): Homeostasis model assessment is more reliable than the fasting glucose/ insulin ratio and quantitative insulin sensitivity check index for assessing insulin resistance among obese children and adolescents. Pediatrics 115: 500-503.

21. The Asia-Pacific Perspective: Redefining Obesity and its treatment. Sydney, Australia, Health Communications Australia Pty Limit 2000.

22. Choi KM, Kim JH, Cho GJ, et al. (2007). Effect of exercise training on plasma visfatin and eotaxin levels. Eur J Endocrinol 157: 437-42.

23. Ruchat SM, Mottola MF (2013): The important role of physical activity in the prevention and management of gestational diabetes mellitus. Diabetes Metab Res Rev 29: 334-346.

24. Seshadri KG, Ananthakrishnan V, Tamilselvan B, et al. (2012): Effect of mild physical activity in obese and elderly women with type 2 diabetes. Indian J Endocrinol Metab 16: 453-454.

25. Zahorska-Markiewicz B, Janowska J, Olszanecka-Glinianowicz M, et al. (2000): Serum concentration of TNF- $\alpha$ and soluble TNF- $\alpha$ receptors in obesity. Int J Obes Relat Metab Disord 24: 1392-1395.

26. Hotamisligil GS, Arner P, Caro JF, et al. (1995): Increased adipose tissue expression of tumor necrosis factor- $\alpha$ in human obesity and insulin resistance. J Clin Invest 95: 2409-2415.

27. Kern PA, Saghizadeh M, Ong JM, et al. (1995): The expression of tumor necrosis factor in human adipose tissue. Regulation by obesity, weight loss, and relationship to lipoprotein lipase. J Clin Invest 95: 2111-2119.

28. Dandona P, Weinstock R, Thusu K, et al. (1998): Tumor necrosis factor-a in sera of obese patients: fall with weight loss. J Clin Endocrinol Metab 83: 2907-2910.

29. Katsuki A, Sumida Y, Murashima S, et al. (1998): Serum levels of tumor necrosis factor-alpha are increased in obese patients with noninsulin-dependent diabetes mellitus. J Clin Endocrinol Metab 83: 859-862.

30. Tsukui S, Kanda T, Nara M, et al. (2000): Moderate-intensity regular exercise decreases serum tumor necrosis factor-alpha and $\mathrm{HbA}(1 \mathrm{c})$ levels in healthy women. Int J Obes Relat Metab Disord 24: 1207-1211. 